\title{
Participatory Parity and Indigenous Decolonization Struggles
}

Author: Michael Elliott

Available from: http://onlinelibrary.wiley.com/doi/10.1111/1467-8675.12235/full

First published: 2 August 2016

DOI: $10.1111 / 1467-8675.12235$

\section{Introduction}

The discursive environments of settler-colonial societies today exhibit a general hostility towards Indigenous normativities and interests of decolonization. While it is more inclusive of Indigenous actors and cultures than has been true of past eras, public discourse tends to remain structured around distinctly Western histories of political thought and experience, and is premised on the continued dispossession and disempowerment of Indigenous peoples at a fundamental level. The claimed result is that the essential violences of settlercolonialism are not simply reproduced, but in fact further advanced, even as public attention is ostensibly directed towards addressing them. ${ }^{1}$ Some now call, accordingly, for Indigenous actors to turn away from these hostile discursive environments as a matter of urgency, and instead to focus energies on independent programs of cultural, social, spiritual, and physical rejuvenation as a means to decolonization. ${ }^{2}$

Given the serious alterations to established arrangements of social and political life that will be necessary if meaningful progress is to be made to address the ongoing (as well as historical) injustices of settler-colonialism, fostering a more hospitable discursive environment in these societies seems essential. It is through public discourse that both justifications for, and the specifics of, such alterations must ultimately be worked out, and so cultivating an environment more congenial to this kind of process is vital. This means not simply achieving greater inclusivity in respect of Indigenous interests and normativities, but also opening up the fundamental norms, values, and assumptions that presently structure the discursive sphere to critical examination and transformation. The underlying grounds of public discourse must, in other words, be substantially unsettled if steps towards genuinely decolonial - or even just decolonizing - futures are to be made.

Clearly, this is no simple task. But one theoretical approach that has the potential to assist in it is the model of reflexive-democratic politics articulated by Nancy Fraser. ${ }^{3}$ Though not formulated in specific conversation with settler-colonial contexts, Fraser's theorizing nevertheless speaks to the challenges faced there in a quite direct way. Her aim is to establish a means by which forms of deep difference and disagreement around the constitutive features of justice (and, by extension, the political in a more general sense) can be rendered a more prominent, regular, and productive feature of public discourse. She proposes to achieve this by elevating something that has long held an eminent place in her work to a position of normative authority in the public sphere: the principle of participatory parity. Through the operation of this principle, Fraser contends, we stand to obtain a way of successfully opening up the underlying features of the political to forms of deep contestation and scrutiny, and, crucially, of moving to reconfigure them along more defensible lines. My aim in this article is consider the extent to which this model of participatory parity seems capable of meeting the specific challenges faced in settlercolonial contexts, and whether it could, therefore, provide a theoretical route towards a more progressive discursive environment therein.

The discussion is organized as follows. Section two unpacks the complaint raised against the prevailing conditions of public discourse in settler-colonial societies by focusing on recent 
Indigenous critiques of the politics of recognition and reconciliation - which currently represents something of a standard language of justice in most liberal settler-colonial societies. Section three then turns to introduce Fraser's theoretical project in more detail, clarifying the problematic behind it and elaborating on its basic consonance with the challenges faced in settler-colonial contexts. Sections four, five, and six shift focus to the "reconstructive" side of Fraser's theorizing. First sketching out the reflexive normative architecture of the principle of participatory parity (section four), I then draw out the more distinctive and specific demands that the settler-colonial situation places upon it (section five), and in section six consider its potential to successfully respond to those demands.

Overall, I argue that participatory parity promises an effective means by which many of the exclusionary and hostile features of the settler-colonial public sphere might be successfully problematized at the public level. However, its capacity to oppose the subordination of Indigenous normativities, and to therefore pave the way towards a discursive environment truly congenial to a decolonizing politics, remains ambiguous. Ultimately, this is due to the rootedness of participatory parity within a distinctly Western idiom of political thought and experience, and its internal drive to reposition this abstract universalism as the overarching normative authority on the political landscape in general, and in Indigenous social realities more specifically. While a partial response may reside, I will suggest, in the agonistic implications of participatory parity, its capacity to meet the challenges posed by settlercolonial contexts and its relationship with justice remain uncertain. Perhaps the greatest benefit of its application in respect of the settler-colonial situation, though, is its tendency to publicize, rather than conceal, this uncertainty.

\section{Hostile Discursive Environments}

Concern about the hostile character of the settler-colonial public sphere has been at the heart of much critique in the contemporary period. Examinations of prevailing norms around matters of political authority and organization, ${ }^{4}$ gender and sexuality, ${ }^{5}$ law, ${ }^{6}$ health, and relationships to land and ecosystems, ${ }^{8}$ among others, have sought to shed light on the extent to which Indigenous normativities are excluded, marginalized, or otherwise denigrated in the contemporary public sphere. Many of these studies have also attempted to show how this represents not only a legacy of colonial domination, but also an active frontier of colonial expansion and consolidation.

A prominent focus for such critique in recent years has been the politics of recognition and reconciliation that, over the past few decades, has emerged as the common vernacular of justice in most liberal settler-colonial contexts. Based on the identification and formalization of special rights and statuses among Indigenous groups, and on the need to move towards futures of mutual welfare and prosperity between Indigenous and settler peoples, the liberal recognition-reconciliation paradigm appears to have presided over a comparatively progressive phase in settler-colonial history. Under its aegis, many groups have been able successfully to make claims to secure increased land and self-government rights and to negotiate new forms of resource management and revenue sharing agreements with the state and industry, as well as promoting greater awareness of, and sensitivity to, Indigenous cultures in the public sphere. There has also been a marked growth in public acknowledgement of (at least some of) the more acute violences of colonial history, and accompanying commitments by the state to address their enduring consequences.

However, despite this ostensibly progressive face, and notwithstanding the important local improvements often realized, critics argue that public discourse within this paradigm is in fact premised on a profound misrecognition of Indigenous peoples. Rather than being conceived in terms of a reciprocal relationship between partners of equal status, recognition 
is instead commonly received and discussed in the public sphere in terms of a demand acting upon the settler/state gaze - that is, as a call for that gaze to be modified so as to more appropriately acknowledge the distinctive place that Indigenous peoples hold in contemporary society (as well as historically). ${ }^{9}$ While this might lead towards some significant alterations to social arrangements, it nevertheless also denies, or renders basically irrelevant, the claim to equal standing of the recognitive gaze of Indigenous peoples. The settler state is presumed to possess a legitimate power (if also now an obligation) to recognize, but to be free from needs of recognition in turn. The language of "reciprocity" and "mutuality" around which public discourse ostensibly turns thus actually veils a clear disparity in terms of the status of the parties. Indigenous peoples are present here merely as objects of recognition; their status as sovereign peoples and hence as equal agents is denied.

The consequence, Glen Coulthard claims, is not just symbolic but material. Rather than offering a means to address the root injustices of settler-colonialism, the politics of recognition in fact reinscribes those injustices at a fundamental level by imposing settler sovereignty as the essential framework within which "progress" is to be conceived and pursued. In doing so, it works "to reproduce the very configurations of colonialist, racist, patriarchal state power that Indigenous peoples' demands for recognition have historically sought to transcend." ${ }^{10}$ Settler institutions are reaffirmed as the overriding authority in respect of Indigenous lands and peoples, and settler normativities are positioned so as to dictate the essential context and form of Indigenous self-government. This is starkly evident through "modern treaty" negotiations in Canada, for instance, where the state unilaterally determines many aspects of the negotiating process, as well as the parameters within which Indigenous self-government is to be realized. ${ }^{11}$ Transfers of power are, as Paul Nadasdy puts it, paid only in the "currency of territorial sovereignty," ensuring that the basic shape of both the "self" and "government" conform to settler expectations and can be made to slot neatly into the existing jurisdictional matrix of the state. ${ }^{12}$ The fact that this often involves locking Indigenous communities into norms of social organization and governance that were forcefully imposed in past colonial eras, and thereby suppressing Indigenous normativities and opportunities for genuine self-determination, is masked by the banner of progress and recognition under which it is conducted.

Importantly, though, the concern here is not simply that an existing context of domination is prone to become replicated through the "advancements" that the recognition paradigm makes available; it is also that the asymmetrical arrangements of public discourse serve to further entrench the colonial order on the contemporary landscape, rendering it more robust at its normative roots and thus more difficult to resist and remove. The politics of recognition works both to promote greater dependency on state structures within Indigenous communities - such that the limited, but nevertheless often vital, protections it affords in the form of "special" rights can be upheld against private and corporate interests-and to further normalize the colonial framework on the political landscape, including in the minds of Indigenous actors. Coulthard and others worry that, whether motivated to adopt (or adapt to) the contours of the recognition paradigm due to a lack of viable alternatives for advancing crucial social and political agendas, or as the result of a genuine belief in the outcomes it promises, participation within its confines leads to a deeper psychological acceptance of the settler-colonial order as the essential frame within which Indigenous futures are to be thought and pursued. The concern is that operating within the constrained space of recognition threatens to diminish not only practical opportunities to oppose the normative foundations of the existing colonial order, but also, through the cultivation of "colonial subjectivities," basic interests in doing so. ${ }^{13}$ The combined result is that Indigenous actors become increasingly drawn towards "paths of least resistance" wherein the focus falls merely on reorganizing, and extracting gains from, 
the internal workings of the colonial order. ${ }^{14}$ And the basis of continued resistance to the foundations of that order is gradually eroded.

Critics of the liberal recognition paradigm in this way aim to demonstrate how the underlying arrangements of public discourse engender a deep hostility to Indigenous normativities, and that this not only reflects a difficult legacy of a colonial past but also marks one of settler-colonialism's principal contemporary frontiers. Some call, accordingly, for Indigenous actors to "turn away" from these hostile environments and to refocus energies inwardly on programs of cultural, social, spiritual, and physical rejuvenation. ${ }^{15}$ Where continued participation remains essential, or even (for some) beneficial for some dimensions of well-being, the view is that it must be conducted in a much more critical and watchful mode than has become usual. ${ }^{16}$ Dale Turner has even suggested entrusting participation only to a special class of trained, skilled mediators "word warriors" 17 - versed in Indigenous as well as Western normative languages, and thus more able to absorb and resist the co-optive forces encountered - although others fear that even this might dangerously underestimate the threat posed. ${ }^{18}$ What is clear is that the prevailing discursive environment is regarded by many as a precarious and fraught platform for Indigenous struggles, and represents largely unpromising ground for the emergence a politics of justice capable of supporting moves towards decolonial futures. If genuine progress in that direction is to be made possible through public discursive channels, a fundamental reshaping of the contemporary discursive environment seems necessary.

\section{A Reflexive Approach to Deep Contestation}

Fraser's reflexive-democratic approach to justice recommends itself as one potential way in which this might be achieved. It is necessary, however, to first clarify the diagnostic picture that informs her project. This is especially so given that there would appear, at first blush, to be a significant distance between that picture and the challenge faced in respect of settlercolonial contexts. There, as I have portrayed it, it is in effect the enduring rigidity of a discursive environment hostile to Indigenous normativities and interests that is at issue. Fraser's attentions, in contrast, fall squarely on contexts where a broad destructuring of the public discursive sphere is already in process. She finds this to be an increasingly common feature of the present era. The contemporary public sphere is replete with disputes in which disagreement extends beyond merely substantive or "first-order" questions of justice such as, for instance, what constitutes a fair distribution of wealth and other resources - to also encompass the constitutive parameters of justice as a concept. These emergent forms of "meta-dispute" tend to gather, she suggests, about three primary "nodes": ${ }^{19}$

1. The "what" of justice - referring to the basic 'substance' that a relation of justice/injustice measures. In today's disputes, claims couched in the familiar grammar of redistribution (which places the substance of justice firmly in the economic order of society) regularly butt up against claims couched in grammars of recognition (locating its substance in the status order) and representation (locating it in the political constitution of society). Since these grammars each indicates a conceptually distinct species of injustice respectively:maldistribution, misrecognition, and misrepresentation - each resists being collapsed into the others. ${ }^{20}$ Consequently, it is now common for there to be no shared or settled way of describing injustice even when there is general agreement that an injury of some kind has occurred.

2. The "who" of justice - referring in one sense to assumptions about the proper moral subject(s) of justice and, in another, to the correct circumscription of political space and authority in relation to matters of justice. Disputants today regularly hold 
different presumptions about the appropriate subject of justice. While some posit that only the individual human subject ought to count, others maintain that particular types of group or even some non-human subjects also qualify. At the same time, disputants often hold importantly different views as to the appropriate bounding of interests, obligations, and authority relevant to justice. Where some presume the territorial state is the only proper (or viable) unit of justice, others argue for smaller, subnational units; for larger (though non-universal) units such as Europe or Islam; or even for a cosmopolitan or global frame. ${ }^{21}$

3. The "how" of justice - referring to assumptions about the proper means of resolving disputes and addressing senses of injury and discontent. Insofar as disputants today hold different and conflicting views on the "what" and "who" of justice, they also tend to disagree on precisely how progress in these disputes can and should be made. Disagreement on the application of justice naturally follows expanded contestation over its proper substance and shape.

As public contestation leaches into the meta-order, disputes take on something of a "freewheeling character," since no sooner do first-order questions arise than they "become overlain with meta-disputes over constitutive assumptions, concerning who counts and what is at stake." 22 The "normal" flow of public discourse is thereby disrupted. Disputes take on an increasingly "abnormal" character, as the basic parameters of justice become themselves everywhere drawn into the field of contestation.

If this diagnostic focus seems to place some distance between Fraser's project and the settler-colonial situation, the normative stance she adopts towards the moment of destructuring helps to close it.

In one sense, of course, Fraser observes, the transition to "abnormality" in the public sphere carries distinctly negative connotations. The breakdown of shared criteria and institutions by which to organize disputes and evaluate competing claims threatens to undermine capacities to coordinate effective action against injustice. The destructuring of the discursive sphere in this way brings the possibility that some experiences of injustice will be further distanced from a viable means of redress as a result. But this is only part of the story. For the moment of destructuring also signals a loosening of the hold that an (evidently) exclusionary bank of norms and assumptions previously exerted over disputes. The flourishing of divergent grammars of justice thus brings new opportunities for hitherto concealed or underappreciated forms of injustice to be elevated to public prominence, and for collaborative work to address them to begin. The transition to abnormal discourse is therefore not simply an empirical phenomenon demanding a response; it is also, for Fraser, something to be celebrated and actively fostered. The "reconstructive" project set up by her diagnostic picture is, then, despite a somewhat discordant focus, directed towards tackling the kinds of deep subordination and exclusion at issue in settler-colonial contexts. Her aim is to find a way to open up public spheres to forms of "abnormal" discourse wherever local conditions presently inhibit its emergence, as well as to respond to the complexities that are inevitably associated with the transition to such contestation in the public sphere.

This leads Fraser to seek a departure from the more conventional ways of thinking about justice in the Western tradition. Our "familiar theories of justice," she notes, are formulated in light of circumstances - real or imagined - in which a substantial level of agreement exists amongst disputants on the underlying parameters of justice. ${ }^{23}$ As such, they are tailored for, and usually seek to create or preserve, conditions of normality. Not only does this mean they lack resources to successfully process forms of meta-dispute, but also that they inherently press towards forms of closure around the basic meaning and shape of justice, thus stifling opportunities for new or as yet unaccounted for injustices to become 
visible and ground claim-making in the public sphere. The inappropriateness of these conventional approaches is therefore not just a matter of practical inefficacy; it is also, for Fraser, a matter of a more elementary internal misdirection. While we must undoubtedly aim to respond to contemporary disputes in a way that can "strengthen diminished capacities of adjudication and redress, ${ }^{24}$ the imperative must also be to guard against any course that "risks instating a new, restrictive predefinition of what counts as an intelligible claim for justice. ${ }^{25}$ Whatever closures are constructed and relied upon in order to make effective action against injustice possible, a clear and active form of openness must be retained if new restrictive orders of normality are to be avoided.

This insistence on valorizing the moment of opening alongside the moment of closure brings Fraser to try to "scramble" a divide commonly constructed in political theory between committed defenses and critiques of modernity. ${ }^{26}$ One of the most useful syntheses of this clash is provided by Stephen White when he depicts it as a meeting of conflicting senses of responsibility. ${ }^{27}$ For the dominant, "modern" strands of the Western tradition - those modes of theorizing against which Fraser most directly sets her stall - the primary motivation of political reflection, White observes, is the "responsibility to act." ${ }^{28}$ Deriving from an encounter with the everyday pressures of physical and political life, this sense of responsibility reflects a "moral-prudential obligation to acquire a reliable knowledge and to achieve practical ends in some defensible manner." ${ }^{29}$ As such, it carries an impetus towards the production of "action-coordinating" forms of knowledge: contributions that directly address the encountered pressures of physical and political life, and which, in doing so, lend themselves to order, conviction, and tractability in responding to those pressures.

In contrast, White finds, "postmodern" streams of political thought tend to privilege a "responsibility to otherness." ${ }^{30}$ Here, the emphasis of political and ethical inquiry falls less on the themes of action and order that dominate the modern mindset, and more on tracking the ways in which that "modern cognitive machinery operates to deny the ineradicability of dissonance" - or, put differently, the inevitability of Otherness - within the world it engages. ${ }^{31}$ Typically associated with a "constitutive" notion of social pluralism, where difference and disagreement stand as inevitable features of political life, ${ }^{32}$ this alternative sense of responsibility derives from the expectation that any human construct inevitably spawns a perennially indeterminable set of "others" that, whether existing in possibility or in fact, also partially constitutes that construct itself. The consequence, from this view, of meeting the modern responsibility to act is that it "always requires one, at some point, to fix or close down parameters of thought and to ignore or homogenize at least some dimensions of specificity or difference among actors. ${ }^{\prime \prime 3}$ Accordingly, the postmodern responsibility to otherness compels a contrasting mode of critique; one that possesses, instead, what White calls a "world-disclosing" impetus. ${ }^{34}$ The overriding urge from this direction is to disturb the self-certainties that lie behind the modern perspective, and to demonstrate the violence towards otherness that exists within the worlds its proponents seek to defend or construct.

In positing the co-essentiality of closure and openness in the way we approach justice, Fraser points to the importance of honoring both of these senses of responsibility and refusing to let one eclipse or gain overall precedence over the other. If we aim only to reconcile difference and to return order and stability to public discourse, we lose sight of the responsibility to otherness and thus risk entrenching arbitrary exclusion and violence in a new normal order of things. ${ }^{35}$ Alternatively, if we revel only in the moment of opening and the exposure of difference and disagreement that it brings, the forms of stability required to move against injustice cannot be constructed and we forsake our responsibility to act. In either case, the results are contrary to the interests of justice. Fraser thus insists on rejecting the "false antithesis" that is often constructed between the modern and postmodern 
political dispositions. ${ }^{36}$ Our aim must be to pursue a course that is energized by the tension between them, rather than incapacitated by it.

The theoretical project set up by this diagnostic picture, then, is geared towards obtaining a means by which opportunities can be increased for excluded or minority grammars of justice and political possibility to find purchase in the public sphere, and through which they can begin to take up more equitable roles in determining the broader conditions of social ordering. Furthermore, it aims to do so by breaking with the traditional ways of thinking about justice that have contributed to the construction and maintenance of exclusionary normalities in the political sphere. In this sense, Fraser's project seems to resonate with the challenges presently faced in settler-colonial contexts. The kind of fundamental reconfiguration of discursive grounds aimed at bears close similarity to that which seems necessary if environments more congenial to decolonizing projects are to be fostered. It is therefore towards examining Fraser's response to this diagnostic picture that we now turn.

\section{Reflexivity through Participatory Parity}

Fraser's answer to the problematic of "abnormal justice" centers on the normative functioning of the principle of participatory parity. Although actually presented primarily as a means for processing metadisputes about the "what" of justice, Fraser's theorization of participatory parity comprises the core of her overall reconstructive strategy. It is ultimately towards establishing conditions of participatory parity in the public sphere that the further recommendations she makes in respect of the "who" and the "how" of justice are directed, and it is to the normative authority of participatory parity that those answers remain ultimately accountable. A close examination of this aspect of Fraser's theorizing therefore offers the best insight into the character and implications of her overall approach.

The prominent position afforded to participatory parity is justified on the basis of an apparent connection it holds with the concept of justice in its "most general" form. ${ }^{37}$ In this, Fraser's contention is that for an injury or discontent to be convincingly claimed as a matter of justice - as opposed to, say, an instance of misfortune or misadventure - it must be connected to a morally important imbalance in the social order. Were it not to have roots in this social dimension, the harm felt would not be intelligible as a matter of justice exactly, because it would seem to infer no remedial obligations in respect of other social actors there would be no onus on balancing the scales, as it were. What we are really talking about, then, when we employ the concept of justice in any particular context or in relation to any particular substance, whether propounded in terms of economy, status, representation, or anything else, is some kind of contested disparity in the social order. All grammars of justice deserve to be understood on these terms in at least a basic sense; all (must) represent ways of bringing claimed disparities of social participation to public prominence.

This connection with justice in its most general meaning is useful because it equips participatory parity with a certain versatility. Specifically, it enables it to perform three distinct and crucial normative roles, which together elicit and sustain a reflexive tension between openness and closure: (i) a hospitality function; (ii) an outcome-assessment function; and (iii) a process-assessment function. ${ }^{38}$ It will help to consider these individually.

\subsection{Hospitality Function}

First, the internal connection between participatory parity and the concept of justice (as opposed to any particular conception of it) means that it can serve to establish a "discursive space" that is in principle open to inhabitation by a radical plurality of grammars of justice. Whatever specific grammar disputants employ, all claims relevant to justice ought to be capable of being expressed (in at least a basic sense) as a form of morally relevant disparity 
in the social order. As such, the language of participatory parity is similarly open and intelligible to actors irrespective of the particular view they hold as to the appropriate substance of justice. It thus carries a ready hospitality to both existing and emergent claims of injustice.

\subsection{Outcome-assessment Function}

Second, participatory parity also serves to steer discursive engagements within this space towards the production of practical substantive norms. Because all grammars of justice must fundamentally reflect concern for imbalances of one kind or another in the social order, the norms and institutional arrangements they would recommend can be assessed on an equally fundamental level for their likelihood to promote or inhibit other actors from participating as full peers in any domain of social life. This makes a reliable process of adjudication possible across a plurality of perspectives. Where claims would seem to create or leave intact social disparities that cannot be publicly justified, the effect would be to recast (rather than resolve) unjust imbalances in the social order. For Fraser, then, participatory parity specifies a primary "substantive principle of justice by which we may evaluate social arrangements. ${ }^{39}$ It provides a basis by which assessments can be made across differing accounts of the appropriate substance of justice to ensure that moves to construct substantive norms remain achievable, and thus that the stability and traction needed to act meaningfully against injustice of all kinds is not lost.

Crucially, however, the norms emerging from this discursive arrangement are never fully stable or closed. Rather, because "there is no wholly transparent perspicuous sign that accompanies participatory parity, announcing its arrival for all to see," its supposed substantive embodiment at any given moment remains inherently open to re-interpretation, contestation, and possible revision. ${ }^{40}$ Participatory parity's standing as the "principal idiom of public reason" therefore actually sets the standard for what appears as provisionally justified in the public realm: ${ }^{41}$ the social arrangements advanced in its name can never attain absolute stability (which is not to say that they cannot gain stability at all) but will remain always vulnerable to being drawn back into the field of public contestation once again.

\subsection{Process-assessment Function}

This reflexive arrangement is bolstered by participatory parity's further functioning as an internal legitimacy standard in respect of the communicative processes it hosts and orients. In this third capacity, participatory parity asks whether the processes of public discourse that it supports are themselves equitably arranged, such that no group finds itself systematically disadvantaged vis-à-vis others. Wherever unjustified disparities of participation do exist or emerge within the process - whether the impediment in question relates to formal or informal barriers to participation, marginalization or domination within the process, or anything else - they signal an important deficit of internal legitimacy. As a result, the arrangements of public discourse must themselves be re-examined and potentially altered in view of these disparities, as must (by extension) the social norms that the process has hitherto produced or supported. And so the same principle that establishes the radically inclusive discursive space and which offers a means of processing engagements within it, also sets a standard against which that space can be scrutinized and held to account from the viewpoint of justice. This third function thus "incorporates a meta-level of deliberation about processes of deliberation," ${ }^{42}$ bringing something of the normative weight of participatory parity to bear upon the discursive space itself (rather than simply on the claims advanced within that space). This is of critical importance because it renders the overall process responsive to discontents associated with its internal functioning, and so helps to prevent it from becoming a proxy for deeper and more covert forms of exclusionary closure. 
In Fraser's hands, then, the principle of participatory parity is charged with, and seemingly capable of doing, rather a lot of work. It provides the base for a discursive politics through which a theoretically radical diversity of grammars of justice can not only be given space in public disputes, but also be brought into productive conversation with one another. Progress can, accordingly, be made towards working through differences and disagreements in the production of more generally defensible social arrangements. Importantly, though, any predilections or proclivities towards absolute settlement and closure in this vein are precluded by participatory parity's structural openness. The discursive space it constitutes therefore remains perpetually open and responsive to the arrival of new divergent claims of justice, even as it offers clarity and direction in respect of an empirically existing plurality. This is, then, to be sure, no recipe for a public sphere purged of conflict and disagreement on constitutive (as well as substantive) matters of justice. On the contrary, it means to render unsettling political engagements a more regular feature of political life, and to imbue the norms and institutions that prevail at the public level with a permanent provisionality and openness to contestation. The benefit that trumps these costs, however, is an increased potential to track the interests of justice and to coordinate actions in light of them.

\section{The Demands of the Settler-Colonial Situation}

To what extent might this framework prove capable of the challenge faced in respect of settler-colonial contexts? Does it offer the resources needed to successfully problematize the subordination of Indigenous normativities and interests in the public sphere? And could it help to pave the way for a decolonizing politics of justice accordingly?

Answering these questions requires viewing Fraser's model in two lights at once. In one respect, of course, we must attend to the internal functioning of the normative arrangement she proposes, assessing it for its potential to effectively address the kinds of asymmetry and hostility at issue in settler-colonial contexts. Alongside this, however, we need also to consider it from a more external angle, that is, with an eye to how, irrespective of - or perhaps even because of - its apparent success in the internal sense, the framework of participatory parity might function to re-inscribe certain problematic power relations. The first of these is, I take it, relatively straightforward, but the second could use some elaboration.

Fraser's theorizing around the concept of abnormal justice, as well as the model of participatory parity she sets out in response, are clearly rooted in a distinctly Western tradition of political thought. That Fraser takes up a critical position in respect of many aspects of that tradition, and that she means to effect a significant departure from its more dominant contemporary branches, in no way negates this fact. It pays, then, to consider whether the approach she lays out finds itself caught in the historical dynamic that Edward Said referred to as the "flexible positional superiority" of Western knowledges and normativities. ${ }^{43}$ Said observed that exclusion has only ever represented one, and perhaps even a secondary, factor in the West's drive to secure a place at the center of the modern world. Of arguably greater importance has been the willingness and capability to adapt to include new and emancipatory ideas, whether internally or externally generated, upon encounters with the apparent defects, inconsistencies, oversights, and violence of the prevailing Western normative order. This has enabled new justifications to be constructed for retaining, rather than relinquishing, a position of dominance on the political landscape, even as the injustices associated with that occupation are brought into view.

As James (Sákéj) Youngblood Henderson notes, though, rarely do such reassertions of positional superiority consist in a claim to status as a kind of privileged normative order amongst many; rather, they are generally conducted under a (perpetually re-inscribed) 
veneer of (newfound) universal validity and efficacy. ${ }^{44}$ The adapted normative order is presented as comprehensive, unbiased, culturally empty, and universally applicable - not really "owned" by anyone despite the fact that it is constructed principally through the productive operations and arenas of Western knowledge and filtered outwards into the political sphere accordingly. ${ }^{45}$ The struggles of the oppressed and the colonized are ostensibly absorbed into the purview of an adapted normative order, but one that remains, for all these modifications, structured principally in light of the dominant group's knowledge, experience, culture, and language, and which works to promote these as the carrier of a universal idiom of normative reason. ${ }^{46}$

For Henderson, this represents a key modality of "cultural and cognitive imperialism." ${ }^{47}$ And it has clear political consequences. The dominant normative order manifests also, in light of its apparent universality, as a repository of expectations and standards ready to be deployed in the art of determining the basic arrangements of social and political ordering (for all peoples) on the political landscape. Actors and institutions most able to speak with and through this normative language also find within themselves entitlement to assume roles as its effective agents, as well as justification for resisting (or ignoring entirely) demands that do not seem to conform with it. ${ }^{48}$ That the imposition of such standards appears eminently more defensible on account of the apparently inclusive and impartial character of the order from which they are derived is precisely the reason for the historical success of this dynamic. Its effect is to underwrite the claims to legitimacy made by Western governance structures, both in terms of justifying their general presence on the political landscapeand, crucially, their right to compel general compliance with those standards, often by coercion or force if necessary.

Fraser, of course, does not develop her model of participatory parity with the explicitly stated intention of applying it to settler-colonial contexts. Nevertheless, the implication is that it can serve as a general framework for justice wherever forms of meta-dispute are present or might arise. But if this model is to prove capable of successfully responding to the kinds of contestation raised in Indigenous critiques of the settler-colonial discursive environment, it must demonstrate responsiveness to concerns associated with its place in this broader historical dynamic. The framework of participatory parity must, in other words, given its Western roots, demonstrate sufficient self-problematizing capacities such that its own political effects, the power relations it is caught up in and reproduces, and the universalizing tendencies it demonstrates, can all be ventilated and examined in an open manner through the course of the discursive politics it would prescribe. If it cannot achieve this, Fraser's model would seem to risk quietly returning an adapted but still distinctly Western normative order to a position of authority on the political landscape, and to thus repeat a crucial part of the problem it is asked to help address.

This second line of examination cannot be set aside while the more practical, or what I have called "internal," functioning of Fraser's model is considered since it strikes at the heart of what is at stake in these disputes. These different scales of critical perspective - to borrow a turn of phrase from Fraser herself - must be combined for a proper assessment to be conducted of participatory parity's potential to meet the challenges faced in settler-colonial contexts, and to promote advancement towards a discursive environment more accommodating of, and responsive to, interests of decolonization.

\section{Considering Participatory Parity}

Combining these two views gives for a rather ambiguous or indeterminate picture of participatory parity's potential. In one light, shifting more towards the internal view, the image is encouraging: the framework of participatory parity seems capable, in principle, of 
accommodating forms of discontent associated with the (general and specific) subordination of Indigenous normativities and interests in the public sphere, and, moreover, offers a means by which this could be brought to bear on disputes in a manner that holds general intelligibility and moral resonance. A pertinent demonstration of this potential comes if we turn the normative standard of participatory parity back on the further aspects of Fraser's reconstructive theorizing.

As indicated, the reflexive framework outlined above represents only one part of Fraser's overall reconstructive strategy. In fact, the three nodes of meta-dispute - the what, who, and how of justice - comprise a sequential set of problems for Fraser, each of which requires its own answer. A solution to disagreements about what justice measures (problem one) is prone to falter if we lack a way of determining who ought to be obligated or entitled to form the community engaging in such reflexive discourse in the first place (problem two). But if we also appreciate that instances of "misframing" are in principle possible, then whatever answer we give to the who of justice must itself have a reflexive structure possessing a determinative capacity (such that we might actually identify cases of misframing in practice) while also remaining inherently open to further contestation (so as to avoid simply settling into a new normal grammar of framing).$^{49}$ This spawns a third problem of how to decide on the correct application of the preferred reflexive criteria in each case.

Fraser's answer to the second in this sequence - the who of justice - relies on a version of the all-subjected principle: ${ }^{50}$

On this view, what turns a collection of people into fellow subjects of justice is neither shared citizenship or nationality, nor common possession of abstract personhood, nor the sheer fact of causal interdependence, but rather their joint subjection to a structure of governance, which sets the ground rules that govern their interaction. For any such governance structure, the all-subjected principle matches the scope of moral concern to that of subjection. ${ }^{51}$

Thus possessing the determinative qualities required, the all-subjected principle also retains a form of reflexive openness due to the fact that the meaning and scope of "subjectedness" is not everywhere obvious and incontestable. Rather, what exactly it means to be subjected to a governance structure is open to some interpretation, as is the precise scope of actors falling within that bracket in practice, however it is defined. The subsequent question of "how" thus becomes one of determining an appropriate meaning and scope for subjectedness in each case, which for Fraser is to be undertaken through deliberation within a global institutional structure of some description. ${ }^{52}$

There is reason to question, though, whether the exclusion-inclusion problematic that Fraser is working with, and which leads her towards the all-subjected principle, is an appropriate fit for settler-colonial bodies of dispute. This is so both in terms of what it takes to be the starting point for addressing disagreements relating to the "who" of justice, and how it imagines resolving them.

The all-subjected principle begins with the governance structures that presently dominate on the political landscape, and concerns itself with the question of how more just communities of inclusion could be formulated around those structures. It thus tends to receive discontents associated with norms of framing principally as complaints of "exclusion from." But however justifiable this focus might be in respect of many contemporary disputes, where it is indeed often the denial of participation in decision-making processes that lies behind discontent, it clearly elides the issue of how those structures have come to hold a position of dominance in the first place - that is, of how they have come to command a justice community at all. Yet this is a key part of what is at stake in Indigenous 
critiques of settler-colonialism: the salience of Western governance structures today is directly linked to the systematic suppression and denigration of Indigenous governance structures, both historically and as an ongoing event. To focus solely on whether or not everyone subject to the coercive power of (for instance) the state is included in the justice public connected to it is to effectively leave unasked the more fundamental question of how that governance structure has attained a position of prominence in the first place and the injustice potentially involved in accepting and reproducing that position.

Furthermore, the "exclusion from" problematic Fraser privileges here also overlooks the fact that this is certainly not the only - nor perhaps even the most pressing - problem faced by Indigenous actors struggling against forms of settler-colonial domination. Rather, as seen through critiques of the liberal politics of recognition, it is often the disabling effects that come with inclusion in a community overwhelmingly dominated by non-Indigenous worldviews, values, interests, and actors that appear paramount. Insofar as some features of Indigenous discontent can be successfully understood to pertain to the "who" of justice in the way Fraser describes it, then, it is not primarily - or at least notonly - "exclusion from" that is at issue; indeed, often something close to the opposite seems nearer the truth. On these terms, any move that would propose to extend boundaries of inclusion outwards (e.g. beyond the existing citizenry of the state to include all those subject to its coercive power) - as the practical implications of the all-subjected principle suggest - risks further minoritizing Indigenous voices and interests in public disputes, and thus potentially exacerbating some of the difficulties already felt. The suitability of the all-subjected principle in these cases therefore appears, irrespective of its apparent reflexive structure, problematic. At the very least, it is contestable on the grounds that it threatens to compound rather than allay some existing forms of injustice.

What ought to be clear, however, is that these lines of critique can be relatively easily reconstructed through the language of participatory parity. It could be claimed, for example, that the selection of the all-subjected principle reflects a clear disparity of social participation since the exclusion-inclusion problematic it is formulated in light of does not sufficiently consider the interests of Indigenous peoples struggling against (and from within) contexts of settler-colonial domination. Similarly, all-subjectedness could be criticized for offering little hope of actually promoting conditions of participatory parity in practice because it seems to press towards a more extreme minoritization of Indigenous voices and interests in the public sphere. A discursive environment configured around the normative authority of participatory parity therefore seems, in principle, to hold promise for foregrounding and contesting power expressions that would otherwise quietly perpetuate arrangements of domination. ${ }^{53}$

While this example looks inwards on Fraser's theorizing rather than outwards on the present conditions of settler-colonial contexts, there is no clear reason to think that the grammar of participatory parity could not be applied more generally in struggles to render important asymmetries of constructive social power and the subordination of Indigenous normativities and interests - as well as actual and potential consequences - more open to public consideration and scrutiny. ${ }^{54}$ Its structural openness seems to make it available as an effective framework for advancing claims in a manner that holds ready intelligibility and moral resonance in the public sphere. Participatory parity would seem to provide, as such, a means by which the hostile features of settler-colonial discursive environments might be successfully problematized through public discursive processes.

However, there is reason to take pause here. For, shifting back towards the external view, there are at least two important doubts that this suggestion of theoretical efficacy provokes. One concerns the rather monological tone in which it is conducted; the other, the potential it carries to arbitrarily reaffirm, or even further entrench, a distinctly Western normative 
order as the overarching authority on the political landscape. Both connect to the dynamic of flexible positional superiority observed by Said and others.

In regard to the first, it must be acknowledged that there are serious limitations associated with any claim to a form of universal validity that is advanced and assessed purely within the bounds of a single normative tradition. That theoretical consistency can be obtained through such monological examination is no doubt important, but it is also insufficient as the basis for a claim to universality. If the credentials claimed (or implied) of participatory parity in this vein are to be more reliably ascertained (or indeed discredited), its form and functioning need to be critically interrogated from other - including, of course, Indigenous normative perspectives. The hospitality of participatory parity does not lack a cultural and political source, and its conditions cannot, therefore, be simply presumed impartial. Rather, participatory parity must be subject to thorough examination from the point of view of those whose struggles and discontents it would claim to accommodate if the hospitality it extends is to be reliably validated.

In regard to the second, it must further be acknowledged that any apparent demonstration of participatory parity's theoretical efficacy has the associated effect of bolstering its claim to a privileged status on the political landscape. Indeed, the more diversified and robust this proof becomes, the more that claim is strengthened. It is, then, precisely the theoretical success of participatory parity that might serve also to cast doubt on its potential to help address some of the more fundamental processes of subordination at stake in settler-colonial contexts. For if the effect of any such "proof" is to re-inscribe an adapted but still distinctly Western normative order as the overarching authority on the political landscape, and in Indigenous social realities particularly, then for all else it might help to achieve, participatory parity would seem to carry a repetition of the broader historical dynamic it is asked to help interrupt. Moreover, it does so at a level that is potentially more difficult to expose and contest.

These concerns each point towards the political character and functioning of participatory parity as a theoretical construct, and its inherent embeddedness in the deeper processes of domination and imperialism at issue in settler-colonial contexts. Both help to illustrate, accordingly, the precariousness of - and perhaps a potential limit to - its claim to support efforts to address the subordination of Indigenous normativities in the public sphere, and to move towards a discursive environment congenial to interests of decolonization. If participatory parity is to go any way towards alleviating such doubts, it must display sufficient self-problematizing capacities. It must demonstrate the potential to bring these issues to the fore within the discursive space it would constitute, and to centralize them as matters of general concern.

This is difficult territory, and deserves far more detailed consideration than I am able to afford it here. However, I want to briefly suggest that there is one possible way in which such self-problematizing capacities might be found within participatory parity. While far from satisfactory as a response to the concerns noted, this might at least indicate its potential to help disturb, if not to escape, the broader dynamics of domination at issue here. This response lies with the agonistic implications of the principle's normative functioning. For it seems logical, conceptually necessary even, that participatory parity should remain accountable to the normative standards it espouses - that is, that it should stand to be criticized on account of being neither constructed under, nor serving to adequately promote, conditions of participatory parity. To cut to the chase, this suggests something of an aporetic structure (in the Derridean sense of the term) that imbues participatory parity with a certain excess. ${ }^{55}$ It implies that the presence, authority, and precise form of participatory parity are perpetually open to becoming problematized - and publicly so by virtue of its own internal logic. While this cannot, of course, assuage concerns about its 
embeddedness in processes of Western colonialism and imperialism, it does suggest an internally generated (and assured) responsiveness to such concerns. The normative functioning of participatory parity seems, in this way, to open a channel by which doubts about its own relationship with justice can be given effective expression, and through the discursive space it would serve to establish. ${ }^{56}$

There is clearly a danger of circularity here: any claim raised against participatory parity on this count would seem, in the same breath, to affirm its universal validity anew. That we are continually returned to the start of the problem in practical as well as theoretical terms is thus a distinct possibility. However, this is not, in my view, a perfect circle. The very fact that we are returned to the problem by the logical operation of participatory parity, rather than taken away from it, is key in this respect. Insofar as discontents of this kind remain perpetually communicable but also irresolvable through the internal logic of participatory parity, they point towards a kind of fissure in its exterior - indeed, perhaps, point simply to the fact that there might actually be an exterior. Though small, this imperfection in the selfaffirming logic of participatory parity could have an important role to play in bringing new democratic possibilities to light in the public sphere, ones that might find themselves better able to speak directly to, and make greater strides towards addressing, the deeper dynamics of domination and subordination encountered in settler-colonial contexts.

The agonistic implications of participatory parity in this regard can provide, at best, only a partial and tentative response to doubts about its complicity in processes of domination and imperialism. This is why its potential to support discursive environments genuinely congenial to interests of decolonization remains ambiguous. On face value, participatory parity promises a framework through which efforts to disturb the hostile and exclusionary grounds of public discourse could be productively channeled, and Indigenous normativities and interests take up a more equitable role in determining social norms. However, its capacity to support such efforts absolutely and without contradiction is far less assured. Consequently, while theoretically offering a route towards an altered, more open, and ostensibly more equitably arranged discursive environment, quite how far participatory parity could take us in that direction in settler-colonial contexts remains uncertain. Perhaps its greatest benefit, however, is precisely its internal drive to publicize this residual uncertainty, and, in doing so, to bring the obstacles and perils that shadow any attempt to foster a more progressive discursive environment in settler-colonial contexts into new light.

\section{Conclusion}

If the discursive environments of settler-colonial societies are to be rendered more congenial to struggles of decolonization in real terms, there is a need to articulate visions of how this might be achieved in theory. Moreover, if the Western tradition is to prove a positive force in such processes, a broader exploration of the tensions and contradictions likely to be encountered in attempts to provide support and assistance is essential. By any reckoning, decolonization is a process that requires not just an unsettling of institutional structures of domination - although it certainly does require this - but also of the assumptions, sureties, and tendencies that are endemic to social and political theorizing in the Western idiom, and which are ingrained in Western normativities. Without this - as Indigenous critique frequently attests - the likely result is to produce new iterations of subordinating logics under banners of progress and justice. At the same time, however, this cannot mean the suspension or sacrifice of a practical critical stance in respect of the material realities of domination. A refusal or failure to directly engage the material structures of domination constitutes, in effect, a form of complicity in their perpetuation. The greatest difficulty lies in bringing these responsibilities together. 
The form of reflexivity Fraser finds in the normative functioning of participatory parity represents one important, and useful, channel through which the tensions that inhere in this task can be explored. As I have suggested, Fraser's answer as to how the underlying grounds of public discourse could be better opened up to critical examination and reconfiguration seems to provide an effective practical stance in respect of the forms of subordination and exclusion currently present in settler-colonial contexts, and their manifestation in hostile discursive environments. A discursive sphere configured in light of the normative authority of participatory parity would bring opportunities for the specific forms of subordination encountered to be problematized and brought to bear on publics in a manner that holds immediate and direct moral resonance. Further, it also opens a channel to the deeper processes behind this subordination, in which participatory parity is itself implicated. Although doubt remains over its capacity to satisfactorily problematize, let alone substantially disturb, these processes, participatory parity does at least provide a platform from which they can become more visible - not just in difficult theoretical terms but, importantly, in terms that are readily and broadly appreciable in the public sphere. Participatory parity might be understood, on these terms, to represent an important focus in efforts to cultivate more progressive discursive environments in settler-colonial contexts.

\section{NOTES:}

\section{I am indebted to David Owen for reading and offering helpful comments on numerous drafts of this article, and to two anonymous referees at Constellations.}

${ }^{1}$ See, for instance: Taiaiake Alfred, Wasáse: Indigenous Pathways of Action and Freedom (Toronto: University of Toronto Press, 2005); Taiaiake Alfred, Peace, Power, Righteousness (Oxford: Oxford University Press, 2009); Glen Coulthard, Red Skin, White Masks: Rejecting the Colonial Politics of Recognition (Minneapolis: University of Minnesota Press, 2014); Leanne Simpson, Dancing on Our Turtle's Back (Winnipeg: ARP Books, 2011); Paul Nadasdy, "Boundaries among Kin: Sovereignty, the Modern Treaty Process, and the Rise of Ethno-Territorial Nationalism among Yukon First Nations," Comparative Studies in Society and History 54 (2012): 499-532.

${ }^{2}$ Coulthard, Red Skin, White Masks; Alfred, Wasáse; Simpson, Dancing on Our Turtle's Back; Jeff Corntassel, "Re-envisioning Resurgence: Indigenous Pathways to Decolonization and Sustainable Selfdetermination," Decolonization: Indigeneity, Education \& Society 1 (2012): 86-101.

${ }^{3}$ The essay "Abnormal Justice" in which Fraser sets out this approach most directly has been published in various formats, including: "Abnormal Justice," Critical Inquiry 34 (2008): 393-422; "Abnormal Justice," in Justice, Governance, Cosmopolitanism, and the Politics of Difference: Reconfigurations in a Transnational World, ed. Günter H. Lenz and Antje Dallmann (Berlin: HumboldtUniversität zu Berlin, 2007), 117-47. For simplicity and consistency, however, throughout this article I refer to the version published as ch. 4 in Nancy Fraser, Scales of Justice (New York: Columbia University Press, 2009), 48-75.

${ }^{4}$ E.g. Alfred, Peace, Power, Righteousness; Nadasdy, “Boundaries among Kin."

${ }^{5}$ E.g. Joyce Green (ed.), Making Space for Indigenous Feminism (Black Point: Fernwood, 2007); Kim Anderson, A Recognition of Being: Reconstructing Native Womanhood (Toronto: Sumach Press, 2000); Scott Lauria Morgensen,Spaces between Us: Queer Settler Colonialism and Indigenous Decolonization (Minneapolis: University of Minnesota Press, 2011).

${ }^{6}$ E.g. John Borrows, Drawing out Law: A Spirit's Guide (Toronto: University of Toronto Press, 2010).

7 E.g. Jeff Corntassel, "Toward Sustainable Self-Determination: Rethinking the Contemporary Indigenous-Rights Discourse," Alternatives, 33 (2008), 105-32. 
${ }^{8}$ Ibid.; Alfred, Wasáse; Simpson, Dancing on Our Turtle's Back.

${ }^{9}$ The claim here relates specifically to practical discourses of recognition at the public level in settlercolonial contexts. Some theoretical accounts of recognition do attempt to respond directly to this problem. See, e.g., James Tully, "Recognition and Dialogue: the emergence of a new field," Critical Review of International Social and Political Philosophy 7 (3) (2004): 84-106.

${ }^{10}$ Coulthard, Red Skin, White Masks, 3.

${ }^{11}$ Stephanie Irlbacher-Fox, Finding Dahshaa: Self-Government, Social Suffering, and Aboriginal Policy in Canada(Vancouver: UBC Press, 2009).

${ }^{12}$ Nadasdy, “Boundaries among Kin," 528.

${ }^{13}$ Coulthard, Red Skin, White Masks; also Alfred, Peace, Power, Righteousness.

${ }^{14}$ Alfred, Wasáse, 40.

${ }^{15}$ Coulthard, Red Skin, White Masks; Alfred, Wasáse; Alfred, Peace, Power, Righteousness; Simpson, Dancing On our Turtle's Back.

${ }^{16}$ Simpson, Dancing on Our Turtle's Back, ch. 1.

${ }^{17}$ Dale Turner, This is Not a Peace Pipe (Toronto: University of Toronto Press, 2006).

${ }^{18}$ Coulthard, Red Skin, White Masks, esp. ch.1.

${ }^{19}$ Fraser, Scales of Justice, 51.

${ }^{20}$ For a challenge to this view, see Axel Honneth's contributions to Nancy Fraser and Axel Honneth, Redistribution or Recognition? a Political-Philosophical Exchange (London: Verso, 2003). For further discussion, see: Rainer Forst, "First Things First: Redistribution, Recognition, and Justification" in Ibid., Justification and Critique (Cambridge: Polity Press, 2014), 109-25.

${ }^{21}$ Fraser, Scales of Justice, 56.

${ }^{22}$ Ibid., 50.

${ }^{23}$ Ibid., 50.

${ }^{24}$ Ibid., 58.

${ }^{25}$ Ibid., 72.

${ }^{26}$ Ibid., 73. Fraser actually uses the terms "agonism" and "discourse ethics" to describe this divide, but it is broader than these labels suggest.

${ }^{27}$ Stephen White, Political Theory and Postmodernism (Cambridge: Cambridge University Press, 1991), 19.

${ }^{28}$ Ibid., 19.

${ }^{29}$ Ibid., 21.

${ }^{30}$ Ibid., 19.

${ }^{31}$ Ibid., 20.

32 See, for instance, Mark Wenman, Agonistic Democracy: Constituent Power in the Era of Globalisation (Cambridge: Cambridge University Press, 2013); Ed. Wingenbach, Institutionalising Agonistic Democracy (Farnham: Ashgate, 2011).

${ }^{33}$ White, Political Theory and Postmodernism, 21.

${ }^{34}$ Ibid., 22.

${ }^{35}$ This is true even if the new normal order is more accommodating of an existing empirical plurality.

${ }^{36}$ Fraser, Scales of Justice, 74.

${ }^{37}$ Ibid., 16. 
${ }^{38}$ The presentation of these as "functions" is my own adaptation. Fraser introduces what I call the outcome-assessment and process-assessment functions of participatory parity at the end of her chapter, "Reframing Justice in a Globalizing World" (ch.2 in Scales of Justice) as outcome and process "notions." What I call the hospitality function of participatory parity is developed in the chapter "Abnormal Justice" in the same book.

39 Ibid., 28.

${ }^{40}$ Fraser, Redistribution or Recognition?, 43.

41 Ibid., 43.

42 Ibid., 44.

${ }^{43}$ Edward Said, Orientalism (London: Penguin, 2003), 7.

44 James (Sákéj) Youngblood Henderson, "Postcolonial Ghost Dancing: Diagnosing European Colonialism," inReclaiming Indigenous Voice and Vision, ed. M. Battiste (Vancouver: UBC Press, 2000), 58.

${ }^{45}$ Linda Tuhiwai Smith, Decolonizing Methodologies: Research and Indigenous Peoples (London: Zed, 1999).

${ }^{46}$ Henderson, "Postcolonial Ghost Dancing."

${ }^{47}$ Ibid., 63.

${ }^{48}$ This is, of course, until a new adaptation becomes necessary.

${ }^{49}$ Fraser, Scales of Justice, 57.

${ }^{59}$ For discussion of the evolution of Fraser's thinking on this matter, see David Owen, "Dilemmas of Inclusion: The All-Affected Principle, The All-Subjected Principle, and Transnational Public Spheres," in Transnationalizing the Public Sphere, ed. Kate Nash (Cambridge: Polity, 2014), 112-28.

${ }^{51}$ Fraser, Scales of Justice, 65.

${ }^{52}$ Fraser sets out the general case for such an institution at pp. 67-71 of Scales of Justice. Its details are not discussed but, essentially, the institution must be global in scope (so as to be able to preside over the full array of framing disputes conceivably set before it) and dialogical in form.

${ }^{53}$ It will be apparent that by criticizing Fraser's answer to the "who" on the basis of her answer to the "what," we are effectively drawn into a kind of circularity. At the risk of fueling confusion here, we might find ourselves wondering: "How do we decide who should be included in the frame of subjects determining the appropriate criteria of framing?" This question is distinct from the one that Fraser seems to ask (in the relationship between problems two and three in her nodal sequence) insomuch as, here, the uncertainty is directed towards the choice of the reflexive criteria itself - which, for Fraser, does seem to need to be answered in a monological way, by political theory, rather than in a reflexive-democratic way (which is reserved merely for the determination of the appropriate application of the criteria in practice). My intention here is to explore the more specific implications of participatory parity. This necessarily leaves open a number of important questions about Fraser's overall reconstructive strategy.

${ }^{54}$ For discussion of social constructive power, see Anthony Laden, Reasoning: A Social Picture (Oxford: Oxford University Press, 2012), ch. 4.

${ }^{55}$ See, Jacques Derrida, Aporias, trans. Thomas Dutoit (Stanford: Stanford University Press, 1993); and for discussion: Samir Haddad, Derrida and the Inheritance of Democracy (Bloomington: Indiana University Press, 2013), esp. ch. 1.

${ }^{56}$ It might be objected that Fraser locates the principle of participatory parity in the domain of the "right" rather than the "good," and that it therefore represents, for her, a moral (as opposed to an ethical) principle whose authority is in fact not open to contestation in the way (or perhaps to the extent) that I suggest. Nevertheless, Fraser does explicitly hold that no incontestable substantiation of participatory parity can arise (e.g.Redistribution or Recognition?, 43) and that the principle thus remains, in a sense, always open. My claim here is that the logical structure of participatory parity 
might actually press further than this: opening up a channel by which its own moral standing can at least be brought into question in a meaningful way through the forms of public discourse it would structure.

\section{Biography}

- Michael Elliott is a Teaching Fellow and postdoctoral researcher at the University of Southampton, UK. His research centers on contemporary theories of justice and democracy. 